STRUCTURAL BIOLOGY COMMUNICATIONS

ISSN 2053-230X

Received 15 March 2021

Accepted 14 April 2021

Edited by A. Nakagawa, Osaka University, Japan

Keywords: iron transport; FEA1; SAD;

Chlamydomonas reinhardtii.

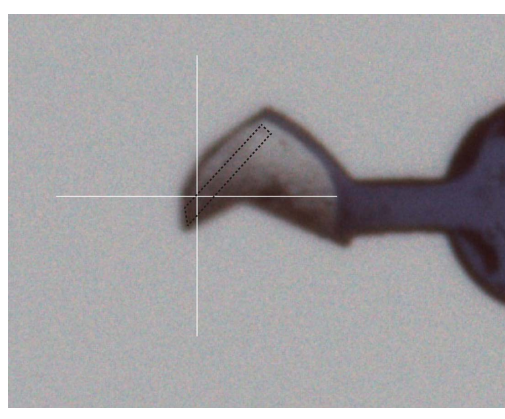

OPEN ๑ ACCESS

\section{Crystallographic analysis and phasing of iron- assimilating protein 1 (FEA1) from Chlamydomonas reinhardtii}

\author{
Linda Juniar, ${ }^{a}$ Vida Adlfar, ${ }^{\mathrm{b}}$ Michael Hippler, ${ }^{\mathrm{b}}$ Hideaki Tanaka ${ }^{\mathrm{a} *}$ and Genji Kurisu ${ }^{\mathrm{a}}$ \\ ${ }^{\mathbf{a}}$ Institute for Protein Research, Osaka University, Yamada-oka 3-2, Suita, Osaka 565-0871, Japan, and ${ }^{\mathbf{b}}$ Institute of Plant \\ Biology and Biotechnology, University of Münster, 48143 Münster, Germany. *Correspondence e-mail: \\ tana@protein.osaka-u.ac.jp
}

As an essential component of protein cofactors, iron is important for all photosynthetic organisms. In Chlamydomonas reinhardtii, iron levels are strictly controlled by proteins such as iron-assimilating protein 1 (FEA1). This periplasmic protein is expressed under conditions of iron deficiency, but its mechanisms of function remain unknown. Because FEA1 has no amino-acid similarity to protein structures in the Protein Data Bank, its crystal structure cannot be solved by molecular replacement. Here, recombinant FEA1 protein lacking the $\mathrm{N}$-terminal signal sequence was successfully purified and crystals of apo FEA1 were obtained by hanging-drop vapor diffusion. Neither selenomethionine substitution nor heavy-atom derivatization was successful; therefore, the phase problem of FEA1 crystals was solved by the native sulfur SAD method using long-wavelength X-rays $(2.7 \AA)$. Laser-cutting technology was used to increase the signal-to-noise ratio and derive an initial structure. This study will lead to further structural studies of FEA1 to understand its function and its links to the iron-assimilation pathway.

\section{Introduction}

The green alga Chlamydomonas reinhardtii is important in many fields of research, including metal metabolism. Metals play essential roles in cells as part of protein cofactors; therefore, their concentrations are tightly controlled as an excess amount can be toxic, while a deficiency leads to inactive metalloenzymes (Hanikenne, 2003; Merchant et al., 2006). As a photosynthetic organism, C. reinhardtii has various irondependent enzymes with vital functions in electron pathways, reactive oxygen detoxification, fatty-acid metabolism and amino-acid biosynthesis (Glaesener et al., 2013).

Rubinelli and coworkers initially characterized the regulation of the expression of HCR1-like protein (H43) (now called iron-assimilation protein 1; FEA1), which is induced by an iron-deficient medium (Rubinelli et al., 2002). FEA1 is a homologue of HCR1 from the marine alga Chlorococcum littorale. Both proteins are highly induced by high $\mathrm{CO}_{2}$ levels and iron deficiency (Rubinelli et al., 2002; Kobayashi et al., 1997; Baba et al., 2011; Sasaki et al., 1998). Studies have shown that the abundance of FEA1 mRNA and protein is greatly increased under conditions of iron deficiency in C. reinhardtii (Allen et al., 2007; Urzica et al., 2012). Importantly, it has been shown that the FEA1 protein is the major protein secreted into the periplasm by iron-deficient $C$. reinhardtii cells, and is expressed coordinately with the FRE1 and FOX1 genes (Allen et al., 2007). It has also been shown to be N-glycosylated (Mathieu-Rivet et al., 2013). 
The exact molecular mechanism of FEA1 in iron assimilation by $C$. reinhardtii is unknown. Its currently proposed function is to concentrate iron in the periplasmic space in the vicinity of iron transporters in order to increase the efficiency of iron uptake under conditions of iron deficiency (Allen et al., 2007). Although FEA1 is not homologous to classical transferrins, a recent study identified ISIP2A as a phyto-transferrin in diatoms functioning in carbonate-dependent iron assimilation, and phylogenic analysis indicates that FEA1 and ISIP2A are related (McQuaid et al., 2018), potentially offering new hypotheses about the function of $C$. reinhardtii FEA1.

Structural characterization of FEA1 will be important to gain a deeper understanding of its role in the iron-assimilation pathway. In crystallography, protein structures are mostly solved by molecular replacement; however, proteins with no homology to structures in the Protein Data Bank (PDB) require experimental phasing. One such phasing method is single-wavelength anomalous dispersion (SAD) using selenomethionine (SeMet) or heavy-atom derivatized crystals. However, if derivatization with SeMet or additional heavy metals, such as mercury or platinum, is not possible, the only option left is native SAD using the $\mathrm{S}$ atoms of methionine or cysteine (S-SAD), a method that has been under development since its first reported use to determine the structure of crambin in 1981 (Hendrickson \& Teeter, 1981). In fact, a number of protein structures deposited in the PDB have been solved by native SAD (Rose et al., 2015). In SAD, using a long wavelength $(2.7 \AA)$ can increase the anomalous signal $\left(f^{\prime \prime}\right.$ of sulfur is $1.5 \mathrm{e}^{-}$) relative to shorter wavelengths; however, both the crystal thickness and the solvent surrounding the crystal may cause strong absorption effects prior to data collection at long wavelengths (Basu et al., 2019). Laser-cutting technology might be the answer to this problem: it can improve the data quality in crystallographic data processing, decrease the dispersion of angle-dependent scale factors and increase the signal-to-noise ratio (Kitano et al., 2005; Basu et al., 2019).

We found that FEA1 can only be crystallized in the apo form without bound $\mathrm{Fe}$ atoms; therefore, we first attempted experimental phasing using SeMet and heavy-atom derivatization. As these approaches failed, we then used S-SAD to phase the diffraction data from FEA1 crystals. Here, we report the crystallization and successful phasing of FEA1 using SSAD at a long wavelength of $2.7 \AA$ coupled with laser-cutting technology.

\section{Materials and methods}

\subsection{Macromolecule production}

The gene fragment encoding the FEA1 protein (Gln19Ala362 of UniProt Q9LD42) was inserted into plasmid pASKIBA2 (IBA). The FEA1 plasmid was designed to express the periplasmic protein with a Strep-tag at the C-terminus. Information on plasmid construction and expression is summarized in Table 1. The recombinant plasmid pASK-IBA2 for FEA1 was transformed into Escherichia coli Rosetta 2 (DE3) cells. A preculture was prepared from a fresh colony
Table 1

Information on the recombinant expression of FEA1.

\begin{tabular}{|c|c|}
\hline Source organism & C. reinhardtii \\
\hline DNA source & DNA fragment generated by synthesis \\
\hline Expression vector & pASK-IBA2 \\
\hline Expression host & E. coli strain Rosetta2 (DE3) \\
\hline \multirow[t]{12}{*}{$\begin{array}{l}\text { Complete amino-acid sequence } \\
\text { of the construct produced } \dagger\end{array}$} & $\begin{array}{l}\text { QPTTTGTRFEGFSYAGNVIGYVNMTMDYCD } \\
\text { IKAAMAAGNFTEALS IYSTGKNSFSGLA }\end{array}$ \\
\hline & 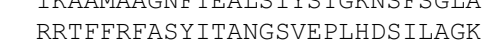 \\
\hline & DTSSLDAAIRAALADGKATLAAGLQVGT \\
\hline & LKYHLHEVDEAYNKIKTYLADGTGNLTN \\
\hline & LVSDASGAPHNVDEAWALWAGGAANNCG \\
\hline & TLSGWASS LGAAMGTTELGKSYVNTAMI \\
\hline & NTVNEMLAAARLSTLNIQAYDAARTNEV \\
\hline & RLLTLLGLQGVSVAAYTADAAAACKRPA \\
\hline & AEVEDAKTMIAVHWAYLEPMLKLRNFKA \\
\hline & SAVTELHHQLTASKLSYKKVAAAVKGVL \\
\hline & SAMGRRSSELGAPQSA I IAANWKCSSKT \\
\hline & LRS IALEVDLQGDHGLSAWSHPQFEK \\
\hline UniProt identifier & Q9LD42 \\
\hline
\end{tabular}

$\dagger$ The 21-residue Strep-tag added to the C-terminus of the native sequence is underlined.

incubated at $26^{\circ} \mathrm{C}$ overnight and was used to inoculate the main culture. The cells were grown in Luria-Bertani medium at $26^{\circ} \mathrm{C}$ and, when the optical density at $550 \mathrm{~nm}\left(\mathrm{OD}_{550}\right)$ had reached $0.5-0.6$, protein expression was induced by adding anhydrotetracycline (to a final concentration of $200 \mathrm{ng} \mathrm{ml}^{-1}$ ) and incubating at $26^{\circ} \mathrm{C}$ for $16-18 \mathrm{~h}$. The cell pellet was collected by centrifugation at $4000 \mathrm{~g}$ at $4^{\circ} \mathrm{C}$ for $12 \mathrm{~min}$.

For protein purification, the cells were suspended in $100 \mathrm{~m} M$ Tris- $\mathrm{HCl} \mathrm{pH} 8.0,500 \mathrm{~m} M$ sucrose, $2 \mathrm{mg} \mathrm{ml}^{-1}$ polymyxin B sulfate and incubated on ice for $30 \mathrm{~min}$. The periplasmic protein was collected by centrifugation at $149000 \mathrm{~g}$ at $4{ }^{\circ} \mathrm{C}$ for $30 \mathrm{~min}$. The supernatant was applied onto an equilibrated Strep-Tactin column (IBA), contaminants were washed through with $100 \mathrm{~m} M$ Tris- $\mathrm{HCl} \mathrm{pH} 8.0$, and the FEA1 protein was eluted with $100 \mathrm{~m} M$ Tris- $\mathrm{HCl} \mathrm{pH} \mathrm{7.5,} 2.5 \mathrm{~m} M$ desthiobiotin. For further purification, the eluted fraction was applied onto an SP HP column (GE Healthcare) and the protein was eluted by a $0-500 \mathrm{~m} M$ linear gradient of $\mathrm{NaCl}$ in $100 \mathrm{~m} M$ Tris$\mathrm{HCl} \mathrm{pH} \mathrm{7.5.} \mathrm{The} \mathrm{purified} \mathrm{FEA1} \mathrm{protein} \mathrm{was} \mathrm{concentrated} \mathrm{in}$ $40 \mathrm{~m} M$ Tris- $\mathrm{HCl}$ pH 7.5 using an Amicon Ultra-15 Centrifugal Filter Unit (10 000 molecular-mass cutoff; Merck Millipore). The protein concentration was estimated by the bicinchoninic acid (BCA) assay.

\subsection{Crystallization}

Initial screening for FEA1 crystals was performed by the sitting-drop vapor-diffusion method using ten commercial screening kits, Crystal Screen, Crystal Screen 2, PEG Rx 1 and 2, PEG/Ion and PEG/Ion 2 (Hampton Research, USA) and Wizard I, II, III and IV (Rigaku, USA), in a 96-well plate using a Mosquito LCP crystallization robot (TTP Labtech). The FEA1 concentration used for crystallization was $10 \mathrm{mg} \mathrm{ml}^{-1}$ in $40 \mathrm{~m} M$ Tris- $\mathrm{HCl} \mathrm{pH}$ 7.5. Droplets consisting of $0.2 \mu \mathrm{l}$ protein solution and $0.2 \mu \mathrm{l}$ reservoir solution were equilibrated against $80 \mu \mathrm{l}$ reservoir solution at 4 and $20^{\circ} \mathrm{C}$. Based on the crystals obtained in the initial screening, crystallization was optimized by the hanging-drop vapor-diffusion method using different 
Table 2

Conditions for crystallization of FEA1.

\begin{tabular}{|c|c|}
\hline Method & Hanging-drop vapor diffusion \\
\hline Plate type & $\begin{array}{l}\text { VDX48 plate with sealant (Hampton } \\
\text { Research) }\end{array}$ \\
\hline Temperature (K) & 277 \\
\hline Protein concentration $\left(\mathrm{mg} \mathrm{ml}^{-1}\right)$ & 10 \\
\hline $\begin{array}{l}\text { Buffer composition of protein } \\
\text { solution }\end{array}$ & $40 \mathrm{~m} M$ Tris- $\mathrm{HCl} \mathrm{pH} 7.5$ \\
\hline $\begin{array}{l}\text { Composition of reservoir } \\
\text { solution }\end{array}$ & $\begin{array}{l}0.2 M \text { ammonium sulfate, } 0.1 M \text { imidazole- } \\
\mathrm{HCl} \mathrm{pH} 6.5,11 \%(w / v) \text { PEG } 3350 \\
30 \%(v / v) \mathrm{MPD}\end{array}$ \\
\hline Volume and ratio of drop & $\begin{array}{l}2 \mu \mathrm{l}, 1: 1 \text { ratio of protein:reservoir } \\
\text { solution }\end{array}$ \\
\hline Volume of reservoir $(\mu \mathrm{l})$ & 150 \\
\hline
\end{tabular}

precipitating agents and additives around the initial conditions. Ultimately, a mixture of $1 \mu \mathrm{l}$ protein sample and $1 \mu \mathrm{l}$ reservoir solution was equilibrated against $150 \mu \mathrm{l}$ reservoir solution, and crystals of FEA1 were obtained in $200 \mathrm{mM}$ ammonium sulfate, $100 \mathrm{mM}$ imidazole- $\mathrm{HCl} \mathrm{pH} 6.5,11 \%(w / v)$ PEG $3350,30 \%(v / v)$ MPD at $4{ }^{\circ} \mathrm{C}$. The crystallization conditions are summarized in Table 2.

\subsection{Data collection and processing}

An FEA1 crystal was picked up by a loop and quickly cooled in liquid nitrogen for data collection. Diffraction data were collected on beamline BL44XU at SPring-8, Harima, Japan using an EIGER X 16M system (Dectris, Baden, Switzerland). S-SAD data were collected on beamline BL-1A at the Photon Factory (PF), Tsukuba, Japan using an EIGER X 4M system (Dectris, Baden, Switzerland). To increase the signal-to-noise ratio, the loop was cut by a laser on station ARNW12A at the PF. All diffraction images were collected at $100 \mathrm{~K}$ and were processed, merged and scaled using XDS/ XSCALE (Kabsch, 2010). The initial model was determined by SAD using autoSHARP followed by autoBUSTER (Vonrhein et al., 2007; Bricogne et al., 2011). It was then used as a search model to solve a native data set collected at a higher resolution on beamline BL44XU at SPring-8, Hyogo,
Table 3

Data collection and processing.

Values in parentheses are for the outer shell.

\begin{tabular}{|c|c|c|}
\hline & Native & S-SAD \\
\hline Diffraction source & BL44XU, SPring-8 & BL-1A, PF \\
\hline Wavelength $(\AA)$ & 0.90000 & 2.70000 \\
\hline Temperature (K) & 100 & 100 \\
\hline Detector & EIGER X 16M & EIGER X 4M \\
\hline $\begin{array}{l}\text { Crystal-to-detector distance } \\
\quad(\mathrm{mm})\end{array}$ & 200 & 61.5 \\
\hline Rotation range per image $\left(^{\circ}\right)$ & 0.1 & 0.1 \\
\hline Exposure time per image (s) & 0.1 & 0.01 \\
\hline Resolution range $(\AA)$ & $38.30-1.90(2.01-1.90)$ & $49.04-2.69(2.76-2.69)$ \\
\hline Space group & $C 2$ & $C 2$ \\
\hline$a, b, c(\AA)$ & $85.75,155.94,129.53$ & $85.44,155.32,129.22$ \\
\hline$\alpha, \beta, \gamma\left({ }^{\circ}\right)$ & $90,102.28,90$ & $90,101.84,90$ \\
\hline Total no. of reflections & 381316 (61723) & 3774689 (40196) \\
\hline No. of unique reflections & 129679 (20765) & $88102(5191)$ \\
\hline Multiplicity & $2.9(2.9)$ & $42.8(7.7)$ \\
\hline Completeness (\%) & $98.9(98.5)$ & $97.4(78.3)$ \\
\hline Mean $I / \sigma(I)$ & 12.0 & $24.4(1.8)$ \\
\hline$R_{\text {merge }}$ & $0.06(0.91)$ & $0.15(0.92)$ \\
\hline$R_{\text {meas }}$ & $0.07(1.11)$ & $0.15(0.98)$ \\
\hline $\mathrm{CC}_{1 / 2}(\%)$ & $99.8(55.0)$ & $99.9(63.8)$ \\
\hline
\end{tabular}

Japan by molecular replacement using Phaser (McCoy, 2017) as part of the CCP4 suite (Winn et al., 2011). Data-collection and processing statistics are summarized in Table 3.

\section{Results and discussion}

FEA1 is a periplasmic protein encoded by the $h 43$ gene (UniProt Q9LD42) in Chlamydomonas. Notably, the construct used in this study comprised amino-acid residues Gly19-Ala362 of FEA1 because the first 18 residues of the $\mathrm{N}$-terminal region are considered to be the signal peptide and were thus omitted. FEA1 was constructed in a pASK-IBA2 vector and heterologously expressed in E. coli Rosetta (DE3) cells as a periplasmic protein with a Strep-tag (LEVDL QGDHGLSAWSHPQFEK) attached to the C-terminus. The recombinant protein was purified using a Strep-Tactin column,

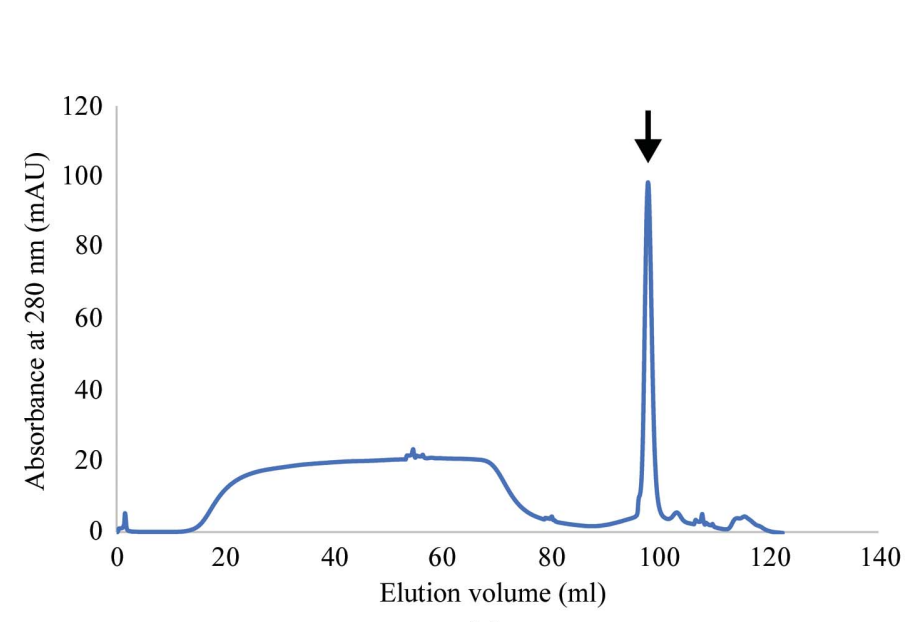

(a)

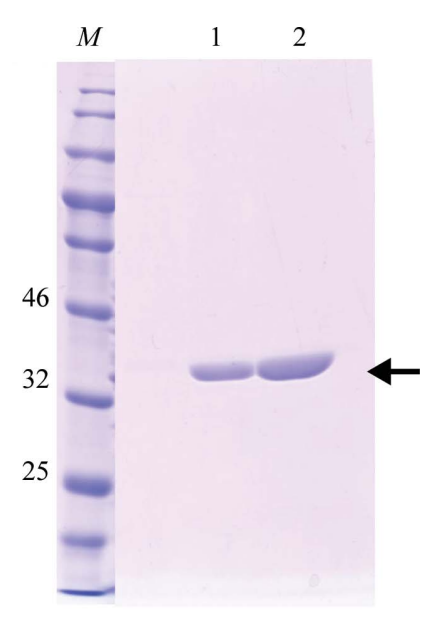

(b)

Figure 1

Purification of FEA1 by cation-exchange chromatography. (a) Chromatogram and (b) SDS-PAGE analysis of purified FEA1. Lane $M$, protein markers (labeled in $\mathrm{kDa}$ ); lanes 1-2, purified FEA1. 
followed by cation-exchange chromatography using an SP HP column. The purified protein was checked by $12.5 \%$ SDSPAGE, which showed a single band with a molecular weight of $38.6 \mathrm{kDa}$ (Fig. 1).

The purified protein was crystallized by the hanging-drop vapor-diffusion method in $200 \mathrm{~m} M$ ammonium sulfate, $100 \mathrm{~m} M$ imidazole- $\mathrm{HCl}$ pH 6.5, $11 \%(w / v)$ PEG 3350, $30 \%(w / v)$ MPD at $4{ }^{\circ} \mathrm{C}$. The crystals were obtained with good reproducibility and diffracted well to $1.9 \AA$ resolution, as shown in Fig. 2. Because there are no proteins in the PDB with a similar amino-acid sequence, we carried out experimental phasing. Firstly, we tried to express SeMet-substituted FEA1 under conditions of methionine-pathway inhibition. However, the expression level was very low, and the amount of sample obtained was not sufficient for crystallization. Next, several heavy-atom derivatives were prepared, including those with thallous acetate, mercury(II) acetate, potassium tetrachloro-

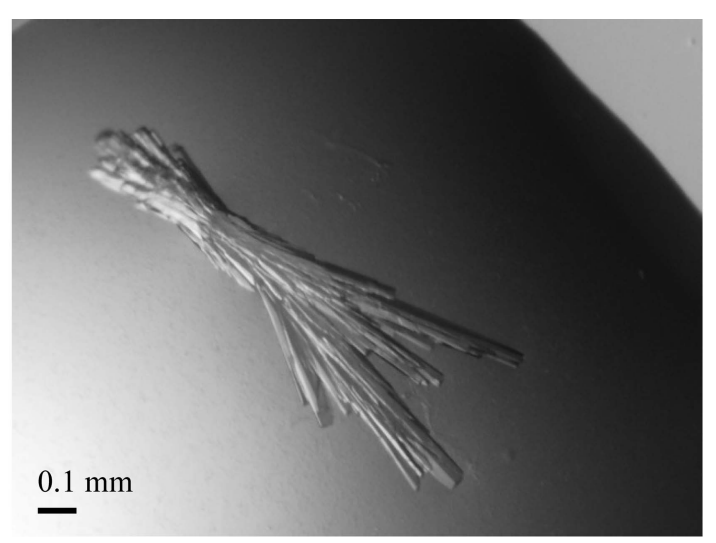

(a)

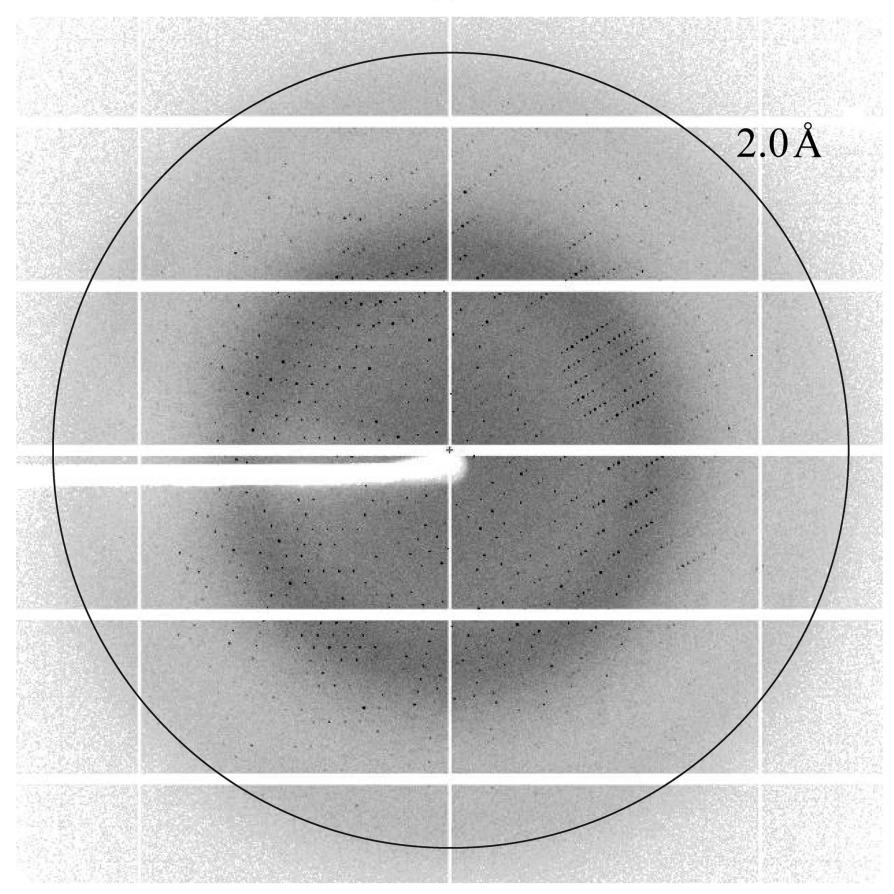

(b)

Figure 2

(a) A crystal of FEA1. (b) Diffraction image of an FEA1 crystal recorded on beamline BL44XU at SPring-8, Hyogo, Japan.
platinate(II), iron(III) chloride and iron(II) sulfate. Unfortunately, none of them were successful in solving the phase problem.

Because FEA1 has $13 \mathrm{~S}$ atoms, we next tried S-SAD to determine the initial phase. Diffraction data for S-SAD were collected using an EIGER X 4M system (Dectris, Baden, Switzerland) at the long wavelength of $2.7 \AA$ on beamline BL-1A at the Photon Factory, Tsukuba, Japan. The diffraction data were processed using $X D S .27$ unmerged data sets were then analyzed using XSCALE_CLUSTER to find isomorphous data sets. In the first attempt, eight data sets were used from the largest isomorphous cluster from one crystal. The data sets comprised 3600 frames with oscillation angles of 0$360^{\circ}$ taken at different crystal positions and kappa angles; however, a native SAD solution was not obtained. In the second attempt, a loop was cut by a laser under the cryogenic conditions to remove the solvent on station AR-NW12A at the Photon Factory, Tsukuba, Japan prior to data collection in order to reduce scattering by the solvent. The crystal of FEA1 was a thin rod-shaped crystal with dimensions of $0.2 \times$ $0.024 \mathrm{~mm}$ as shown by a black dotted line in Fig. 3. The solvent around the crystal was removed as much as possible, and the final distance between the cutting line and the crystal was

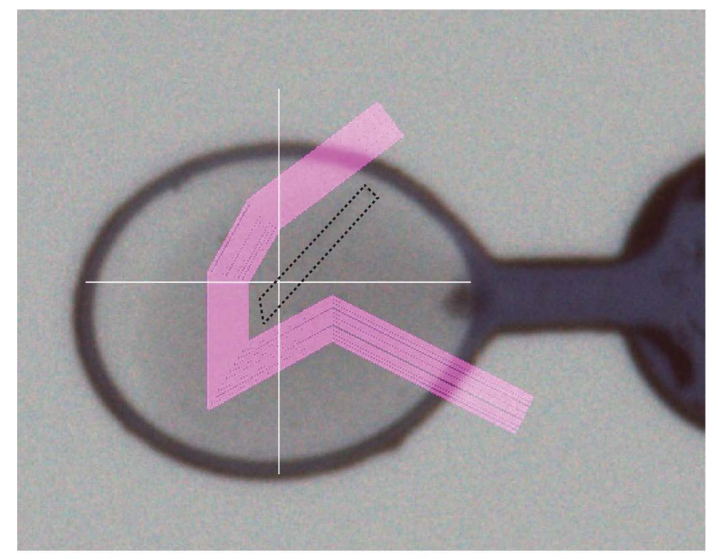

(a)

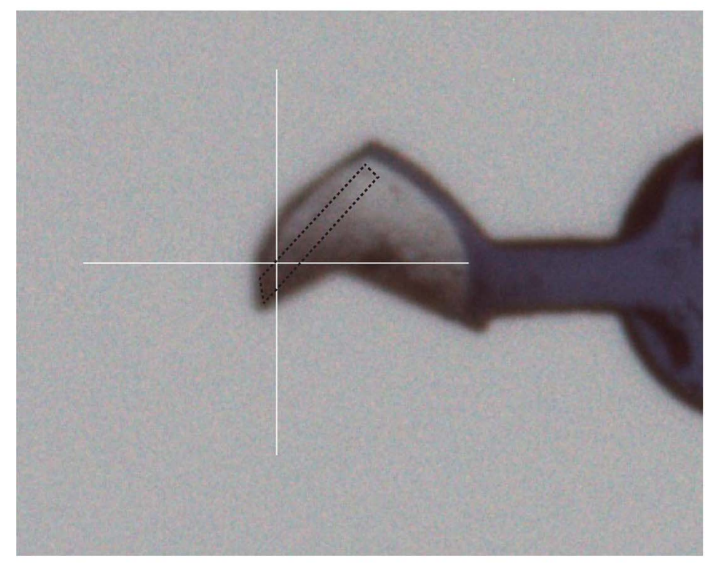

(b)

Figure 3

Laser cutting to decrease the solvent content of the loop. (a) Original loop before laser cutting and the cutting-line pattern (pink line); $(b)$ the same loop after laser cutting. The shape of the FEA1 crystal is shown by a black dotted line. 


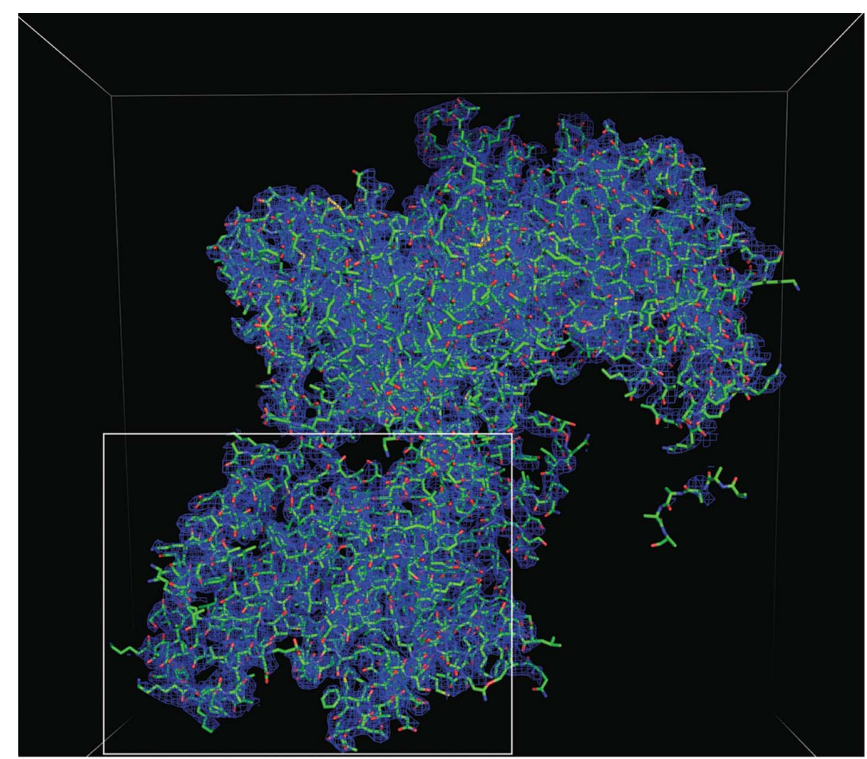

(a)

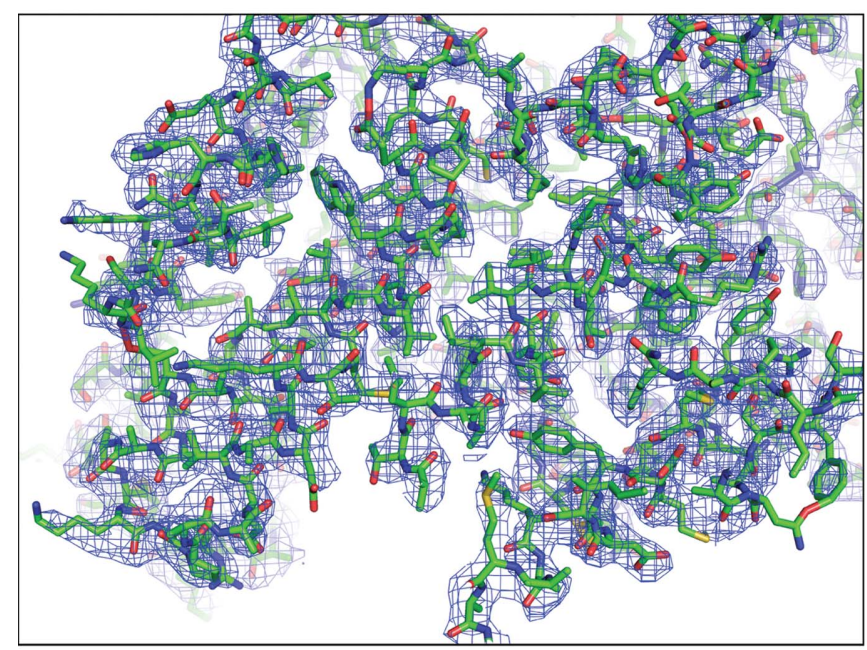

(b)

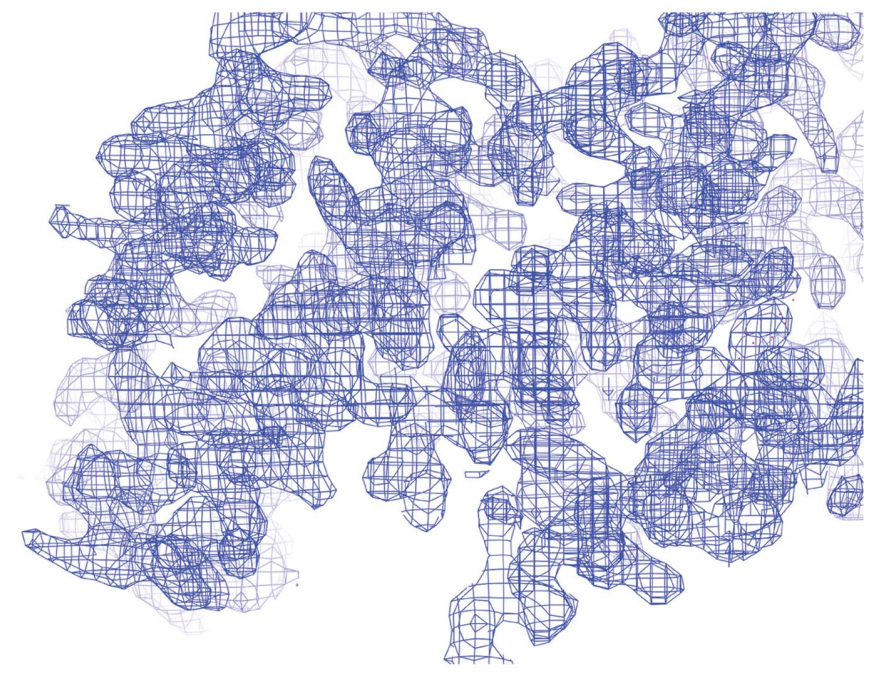

(c)

Figure 4

Initial structure of FEA1 solved by S-SAD. $(a, b)$ The electron-density map is contoured around the initial structure. (c) The experimental electron-density map from autoBUSTER. The figures were generated using PyMOL. about $0.032-0.039 \mathrm{~mm}$. After the laser-cutting process, 29 data sets were collected using the solvent-removed crystals. 16 isomorphic data sets from the first and second data collections were then merged and scaled at $2.6 \AA$ resolution using $X S C A L E$. Finally, the phase was solved by SAD using autoSHARP followed by autoBUSTER (Vonrhein et al., 2007; Bricogne et al., 2011). There were 1060 residues in seven chains, with 1032 residues of the FEA1 sequence in the initial structure (Fig. 4).

The crystal of FEA1, which diffracted to $1.9 \AA$ resolution, belonged to space group $C 2$, with unit-cell parameters $a=85.75, b=155.94, c=129.53 \AA$, $\beta=102.27^{\circ}$. The Matthews coefficient of the FEA1 crystal was $3.37 \AA^{3} \mathrm{Da}^{-1}$, with three molecules in the crystallographic asymmetric unit and $63.5 \%$ solvent content (Matthews, 1968). The initial structure from the SAD solution was used as a search model for higher resolution data sets using Phaser (McCoy, 2017). Model rebuilding and refinement are ongoing.

In summary, we have used S-SAD and laser-cutting technology to solve the phase problem in the crystallographic analysis of FEA1 crystals. This study will lead to further structural studies of FEA1 to understand its function and its links to the iron-assimilation pathway.

\section{Acknowledgements}

We would like to thank the beamline staff of BL44XU at SPring-8 and Dr Naohiro Matsugaki from BL-1A at the Photon Factory for their kind support during data collection under proposal Nos. 2019A6500 and BINDS1597, respectively.

\section{Funding information}

This research was supported by a Grant-in-Aid for Scientific Research (No. 16H06560) to GK from MEXT-KAKENHI, by JST-CREST (JPMJCR20E1) to GK and by funding from the International Joint Research Promotion Program of Osaka University to $\mathrm{MH}$ and GK. $\mathrm{MH}$ acknowledges funding from the Federal states NRW 313-WO44A.

\section{References}

Allen, M. D., del Campo, J. A., Kropat, J. \& Merchant, S. S. (2007). Eukaryot. Cell, 6, 1841-1852.

Baba, M., Hanawa, Y., Suzuki, I. \& Shiraiwa, Y. (2011). Photosynth. Res. 109, 169-177.

Basu, S., Olieric, V., Leonarski, F., Matsugaki, N., Kawano, Y., Takashi, T., Huang, C.-Y., Yamada, Y., Vera, L., Olieric, N., Basquin, J., Wojdyla, J. A., Bunk, O., Diederichs, K., Yamamoto, M. \& Wang, M. (2019). IUCrJ, 6, 373-386.

Bricogne, G., Blanc, E., Brandl, M., Flensburg, C., Keller, P., Paciorek, W., Roversi, P., Sharff, A., Smart, O. S. \& Vonrhein, C. (2011). BUSTER. Global Phasing Ltd, Cambridge, UK.

Glaesener, A. G., Merchant, S. S. \& Blaby-Haas, C. E. (2013). Front. Plant Sci. 4, 337.

Hanikenne, M. (2003). New Phytol. 159, 331-340.

Hendrickson, W. A. \& Teeter, M. M. (1981). Nature, 290, 107-113.

Kabsch, W. (2010). Acta Cryst. D66, 125-132.

Kitano, H., Matsumura, H., Adachi, H., Murakami, S., Takano, K., Inoue, T., Mori, Y., Doi, M. \& Sasaki, T. (2005). Jpn. J. Appl. Phys. 44, L54-L56. 
Kobayashi, H., Odani, S. \& Shiraiwa, Y. (1997). Plant Physiol. 114, S112.

Mathieu-Rivet, E., Scholz, M., Arias, C., Dardelle, F., Schulze, S., Le Mauff, F., Teo, G., Hochmal, A. K., Blanco-Rivero, A., LoutelierBourhis, C., Kiefer-Meyer, M. C., Fufezan, C., Burel, C., Lerouge, P., Martinez, F., Bardor, M. \& Hippler, M. (2013). Mol. Cell. Proteomics, 12, 3160-3183.

Matthews, B. W. (1968). J. Mol. Biol. 33, 491-497.

McCoy, A. J. (2017). Methods Mol. Biol. 1607, 421-453.

McQuaid, J. B., Kustka, A. B., Oborník, M., Horák, A., McCrow, J. P., Karas, B. J., Zheng, H., Kindeberg, T., Andersson, A. J., Barbeau, K. A. \& Allen, A. E. (2018). Nature, 555, 534-537.

Merchant, S. S., Allen, M. D., Kropat, J., Moseley, J. L., Long, J. C., Tottey, S. \& Terauchi, A. M. (2006). Biochim. Biophys. Acta, 1763, $578-594$.
Rose, J. P., Wang, B.-C. \& Weiss, M. S. (2015). IUCrJ, 2, 431-440.

Rubinelli, P., Siripornadulsil, S., Gao-Rubinelli, F. \& Sayre, R. T. (2002). Planta, 215, 1-13.

Sasaki, T., Kurano, N. \& Miyachi, S. (1998). Plant Cell Physiol. 39, 405-410.

Urzica, E. I., Casero, D., Yamasaki, H., Hsieh, S. I., Adler, L. N., Karpowicz, S. J., Blaby-Haas, C. E., Clarke, S. G., Loo, J. A., Pellegrini, M. \& Merchant, S. S. (2012). Plant Cell, 24, 3921-3948.

Vonrhein, C., Blanc, E., Roversi, P. \& Bricogne, G. (2007). Methods Mol. Biol. 364, 215-230.

Winn, M. D., Ballard, C. C., Cowtan, K. D., Dodson, E. J., Emsley, P., Evans, P. R., Keegan, R. M., Krissinel, E. B., Leslie, A. G. W., McCoy, A., McNicholas, S. J., Murshudov, G. N., Pannu, N. S., Potterton, E. A., Powell, H. R., Read, R. J., Vagin, A. \& Wilson, K. S. (2011). Acta Cryst. D67, 235-242. 